\title{
Implant Stability Changes for Nonsubmerged and Submerged Protocols for a Single Implant Mandibular Overdenture Using Ball Attachment
}

\author{
Ahmed Salah $(D$, Karim Foda, Mohamed Farouk Abdalla $(D$, Marwa Abdel Aal $(D$, \\ Amr Naguib $(\mathbb{B}$, and Nouran Abdel Nabi \\ Prosthodontics Department, Faculty of Dentistry, Cairo University, Giza, Egypt \\ Correspondence should be addressed to Nouran Abdel Nabi; nouranabdelnabi@dentistry.cu.edu.eg
}

Received 2 August 2021; Accepted 8 September 2021; Published 21 September 2021

Academic Editor: Vincenzo Iorio Siciliano

Copyright (C) 2021 Ahmed Salah et al. This is an open access article distributed under the Creative Commons Attribution License, which permits unrestricted use, distribution, and reproduction in any medium, provided the original work is properly cited.

Objectives. To compare the changes in implant stability for the nonsubmerged (NS) and submerged (S) protocols for the single implant retained mandibular overdenture using ball attachment throughout a 24-month follow-up. Materials and Methods. Eighty completely edentulous patients were seeking to improve retention of their lower complete denture by installing a single implant in the midline of the completely edentulous mandible. At the day of implant installation, patients were randomized into 2 groups using sealed envelopes: the nonsubmerged (NS) and submerged (S) group. After a 3-month healing period, all patients were randomized using sealed envelopes into ball attachment and CM-LOC attachment. The Periotest readings (PTV) was recorded using the Periotest $M$ device and was recorded every 3 months for the first year and then annually in the second year. The scope of this clinical trial focused only on results of the ball attachment. The Mann-Whitney $U$ test was used for comparison between study groups for independent samples. Two-sided $p$ values less than 0.05 was considered statistically significant. Results. There was no statistically significant difference in the mean change in PTV reading between the NS and S group at the different follow-up intervals. Initially, at the day of pickup (baseline) and 3-month follow-up, the mean PTV reading for the NS was greater than that of the $S$ group $(-4.471 \pm 1.489,-4.391 \pm 1.4727(p=0.913))$, while the $S$ group has shown a greater improvement in PTV than the NS group after 6-month follow-up and continued throughout the 24-month follow-up $(-5.730 \pm 1.7804,-50855 \pm 1.2581$ $(p=1))$. Conclusion. Both the nonsubmerged and the submerged healing protocol have shown reliable Periotest readings using ball attachment for a single implant retained overdenture. The submerged group has resulted in a greater improvement in Periotest readings after the 12- and 24-month follow-up period when compared to the nonsubmerged group although this improvement was not statistically significant.

\section{Introduction}

Branemark first introduced the successful outcomes of the submerged surgical procedure in implant dentistry [1]. The submerged surgical protocol would enhance the process of new bone formation and remodeling by utilizing a two-stage surgical procedure, which first includes implant installation in the underlying bone and then a secondary-stage surgery after a period of osseointegartion [2]. The two-stage surgical protocol has proven to have good short- and long-term outcomes [3-5].
On the other hand, osseointegration has proven to be successfully achieved through a single-stage "nonsubmerged surgical protocol," in which implants and the healing abutment are exposed in the oral cavity during the period of osseointegration $[6,7]$. The nonsubmerged surgical protocol offers several advantages when compared to the submerged surgical protocol as it requires only a single-stage surgery which is more cost effective [8], it is more convenient to the patients reducing postoperative complications, and there is no microgap at the alveolar bone crest level [9]. But, the submerged surgical technique would be indicated in almost 
all cases, specifically in cases where bone augmentation is required, as it will decrease overloading of the implants during the osseointegartion period and would ensure optimum healing [10].

One of the principles of osseointegration is primary implant stability, which is essential for achieving short- and long-term success [11]. Primary implant stability is mainly associated with the mechanical engagement of the implant to the surrounding bone, whereas bone generation and remodeling phenomena determine the secondary (biological) stability $[12,13]$. Bone quantity, bone quality, surgical technique, and implant design are factors that influence primary stability, while primary stability, bone remodeling, and implant surface conditions are considered as important factors that will influence secondary implant stability [14].

The Periotest device and Resonance Frequency Analysis (RFA) using the Osstell device have been considered as noninvasive methods to measure implant stability $[15,16]$. Primary and secondary implant stability measurements using both devices have resulted in reproducible quantitative values. The Periotest is an electronic instrument designed to give quantitative measurements of the damping characteristics of the periodontal ligament surrounding a tooth, thus establishing a value for its mobility $[17,18]$. The Periotest instrument comprises a hand piece containing a metal slug that is accelerated towards a tooth by an electromagnet. The contact duration of the slug on the tooth is measured by using an accelerometer. The software in the instrument is designed to relate contact time as a function of tooth mobility. The result is displayed digitally and audibly as Periotests values (PTVs) on a scale of -8 (low mobility) to 50 (high mobility). The technique has also been used to determine implant mobility, and typical values obtained were defined as ranging from -5 to 5 , thus representing a narrower range over the scale of the instrument than for tooth mobility measurements. A stable implant will exhibit different stiffness characteristics compared with those of teeth that are connected by a periodontal ligament.

Implant supported over dentures has solved some of the problems of mandibular complete dentures. The MC Gill consensus 2002 and York consensus 2009 have stated that two implants installed in the mandible is considered to be the standard of care for completely edentulous patients [19-21]. Harder et al. and Cheng et al. have proved that a single implant installed in the midline can be an efficient treatment option as two implants installed in the mandible $[22,23]$. Cordioli et al. introduced the idea of installing a single implant in the midline of a completely edentulous mandible to retain an overdenture [24]. The single implant retained mandibular overdenture is considered to be a costeffective treatment option which has proved to have medium- to long-term survival rates [24-28].

The choice of the attachment system for the implant retained overdentures is considered to be of great importance as it has an impact on the overall patient satisfaction and the clinical success [29]. Ball and socket attachment has been the most popular unsplinted attachment used to retain a mandibular overdenture because of its simplicity and cost effectiveness [30]. Previous studies have reported that a single implant retained overdenture using ball or locator attachment to support an overdenture have proved satisfactory outcomes [24, 31-34].

The aim of this randomized clinical trial was to compare the changes in implant stability using the Periotest device for the nonsubmerged and submerged protocols for the single implant retained mandibular overdenture using ball attachment for a 24-month follow-up.

\section{Materials and Methods}

The study proposal was approved by the Ethical Committee of the Faculty of Dentistry, Cairo University, on June 13, 2016 (ethical approval No. 16/6/10) and is registered at http://www.pactr.org/(trial PACTR201803003085193). The guidelines of the World Medical Association were implemented in this clinical trial.

Eighty completely edentulous patients were recruited following strict inclusion criteria. All patients received a single implant in the midline of the edentulous mandible. At the day of implant installation, patients were randomized using sealed envelopes into two groups, nonsubmerged (NS) and submerged (S), and a 3-month healing period was allowed for all patients in both groups. The present study has followed the same inclusion criteria, sample size calculation, and all of the clinical relevant procedures of the trail carried out by Aal et al. [35]. All included patients (age ranging from 50-69 years) were recruited following strict inclusion criteria: glycosylated hemoglobin level $\geq 8$, patients seeking to install a single median implant in the mandible, and for whom new dentures will be constructed were included. Patients with any condition that would contraindicate implant placement were excluded.

Patients were instructed to take a dose of $2 \mathrm{~g}$ of amoxicillin 2 hours before surgery. Local anesthesia was given in the lower anterior area; then, a small crestal incision was made in the area of implant installation, guided by the radiographic stent, which was converted to a surgical stent at the day of surgery. The surgical stent had a small opening in the area corresponding to the central incisors to help in implant installation. All implants installed in this study were ZDI implants with a tapered screw vent (Zimmer Dental, Warsaw, Ind), with a diameter of $3.7 \mathrm{~mm}$ and length of $10 \mathrm{~mm}$, and SBM surface treatment which is a Soluble Blast Media of Hydroxyapatite (HA) crystals to create a rough texture, and then, the surface is cleaned with $20 \%$ acid solution. The description of the implant surface is fundamental, as it influences osseointegration and the health of the soft tissues [36, 37].

Drilling was carried out using the Zimmer Dental kit following the manufacturer's instructions. Following implant installation, all patients were instructed to be on Ibuprofen 400-600 mg every 6-8 hours; in addition to that, ice pack or cold compress was given to the patient to use for 2 hours postoperative implant installation.

This clinical trial followed up the changes in Periotest readings (PTV) for the nonsubmerged (NS) and submerged (S) groups after the 3 month of healing period (day of pickup) after which second randomization was followed. 
2.1. Patient Distribution after 3-Month Healing Period (Day of Pickup). During the 3-month healing period, 4 patients have reported failure and 3 patients were counted as dropouts from the submerged group (S). While for the nonsubmerged group 2 patients have reported failure (Figure 1). The number of patients that were recalled after the 3-month healing period was 71: 33 patients in the submerged group (S) and 38 patients in the nonsubmerged group (NS). Failures in the submerged group were probably due to patients having bad oral hygiene during the healing period, while in the nonsubmerged group, they were mainly due to patients not following the instruction to eat soft food during the first few weeks subjecting the implant to great micromovements.

After a randomization process, the patients were divided in 2 groups (submerged vs. nonsubmerged protocol), and after 3 months of healing, they were randomly divided again into 2 groups (ball attachment vs. Cendres and Metaux attachment). In this study, we valued only the cases with ball attachment. The distribution of patients in each of the groups is described in Table 1. Randomization and allocation concealment were carried out by Amr Naguib, as he was responsible for preparing the envelopes used in randomization.

\section{Intervention}

3.1. Pickup of the Attachments. At the day of pickup, the healing abutments in the NS group were unscrewed and the ball (Zimmer dental implants) attachment was screwed in place with a torque of $30 \mathrm{~N} / \mathrm{cm}$, while for the $S$ group, a small crestal incision was made at the area corresponding to the attachment.

The ball attachment (Zimmer dental implants) compromises a male abutment with a gingival cuff height of $2 \mathrm{~mm}$ and $4 \mathrm{~mm}$. The abutment was screwed onto the underlying implant using a specific screwdriver. The housings are made of titanium with a nylon transparent retentive insert that was supplied from Zimmer Company with the ball abutment (Figure 2).

The height of each attachment used in the following study was not standardized as it depends on the amount of mucosa present after healing which was different for each patient. The amount of keratinized mucosa was measured 3 month after healing, and two different ball attachments were used, $2 \mathrm{~mm}$ and $4 \mathrm{~mm}$, accordingly.

After the attachments were screwed in place and the patients were instructed to sit in an upright position and not to move, the Periotest M (Medizintechnix Gulden e.K., Modautal, Germany) was directed to the midbuccal surface perpendicular to the long axis of the screwed attachment, and the tapping rod was directed at the bottom of an attachment as described by the manufacturer, to measure the implant stability (Periotest reading, damping effect $=$ PTV) at the day of pickup (3 months after healing) which is considered to be the baseline reading. Five readings were recorded for each patient, and then, average reading was recorded in the patient file. This reading was considered to be the baseline reading (Figure 3). Ahmed
Salah and Karim Foda were responsible for recording the PTV readings for all groups of patients throughout the 24month follow-up period.

The ball attachment was screwed to the implant with a torque of $30 \mathrm{~N} / \mathrm{cm}$, with the corresponding matrix on top of it, Nylon matrix. The mandibular denture was then modified by cutting a small hole in the area corresponding to the attachment, and a red die was placed on top of the matrix to ensure that there was no interference between the matrix and the fitting surface of the modified denture. The mandibular denture was then checked for proper seating, and the occlusion with the maxillary denture was properly checked. All undercuts were blocked out in both attachments before pickup. The denture was then properly seated in place then a soft mix of Luxa pickup material (DMG) and then added to the hole of the modified denture; the patient was then asked to close in centric occlusion. After complete setting of Luxa pickup, the denture was removed and the pickup of the matrix was checked (Figure 4). All excess Luxa pick material was removed and then polished. Patients were recalled 3 days after pickup to check if there were any premature contacts or areas that required relief. This procedure was carried out for both attachments used in this study.

The Periotest reading (PTV) was recorded for all patients following all instructions that were given at the baseline reading (3 months after healing), five readings were recorded, and then, average was recorded in the patients' file. PTV was recorded every 3 months for the first 12 months and then annually at 24-month follow-up.

After the 3-month healing period, 33 patients were present in the S group and 38 patients in the NS group; 6 patients in the $S$ group refused to have the Periotest readings, and 9 patients in the NS group resulting in a total of 56 patients after the 3-month healing period (baseline). At 3-month follow-up, 1 patient belonging to the ball attachment in the $S$ group died and 1 patient was dropped out in the CM-LOC NS group, resulting in a total of 54 patients at 3-month follow-up. At 6-month follow-up, 2 patients belonging to ball attachment group in the $S$ group were dropped out (1 male and 1 female) resulting in a total of 52 patients at 6-month follow-up. At 9-month followup, 1 patient from the ball attachment group in the $S$ group died (male) and 1 patient from CM-LOC attachment in the NS group died (male), thus resulting in a total of 50 patients at 9-month follow-up. At 12-month follow-up, no dropouts occurred, while at 24-month follow-up, 2 patients belonging to the CM-LOC group in the $S$ group were dropped outs (males), 1 patient in ball attachment group in NS group was hospitalized (female), and 2 patients from CM-LOC group NS were hospitalized (males), thus resulting in 45 patients at 24-month follow-up (Figure 1, Table 1).

Data were statistically described in terms of mean\pm standard deviation $( \pm \mathrm{SD})$. Comparison of numerical variables between the study groups was done using the Mann-Whitney $U$ test for independent samples. Two-sided $p$ values less than 0.05 were considered statistically significant. All statistical calculations were carried out using 


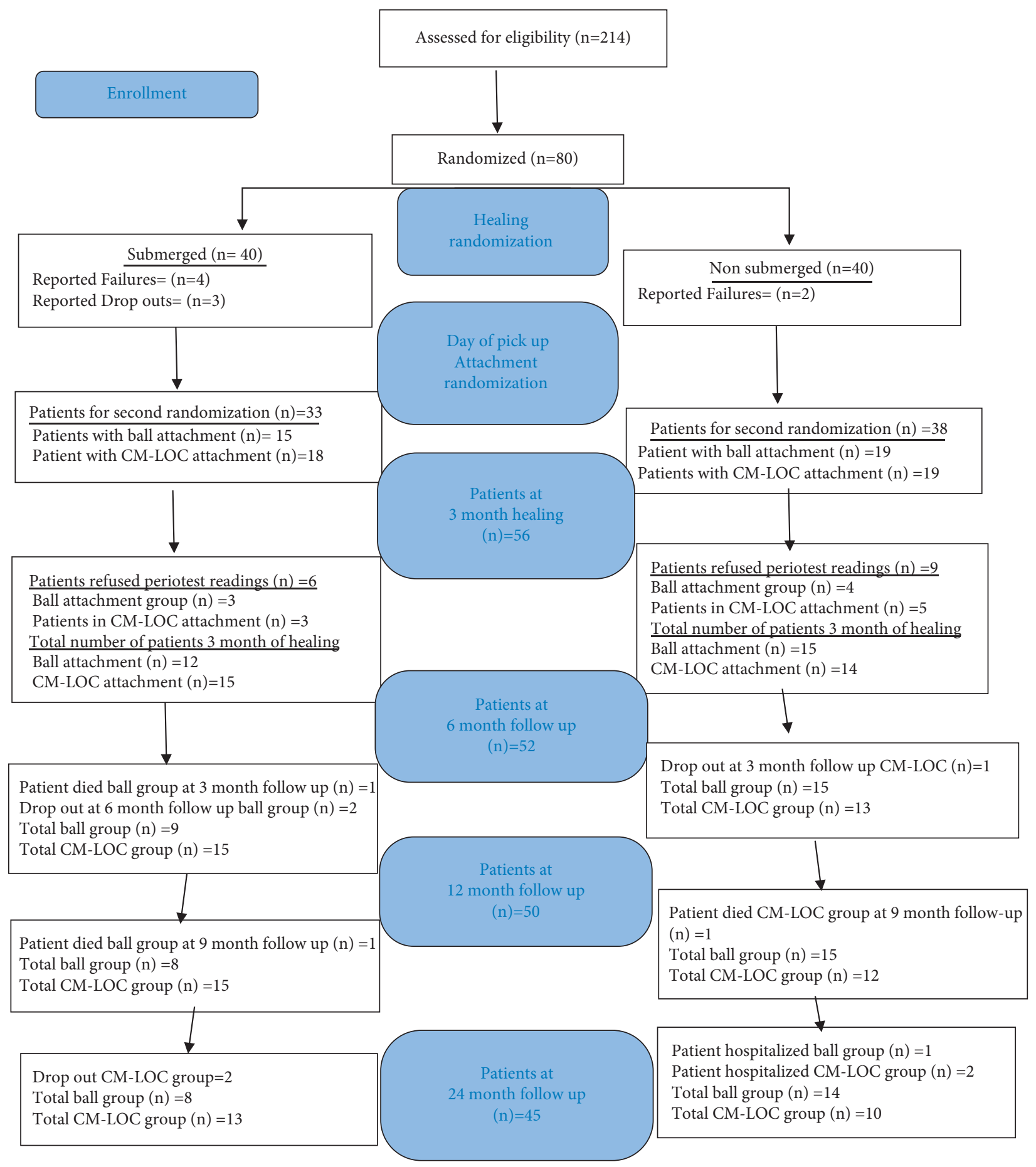

Figure 1: Consort flow diagram.

computer program IBM SPSS (Statistical Package for the Social Science; IBM Corp, Armonk, NY, USA) release 22 for Microsoft Windows.

\section{Results}

The interobserver consistency for the two readings of the PTV that was recorded by AS and KF for both groups, the NS and the $\mathrm{S}$, during the different follow-up intervals using Cronbach's alpha Statistics (Table 2). Results of the interobserver consistency showed a strong agreement for both groups at the different follow-up period, as the values at the different follow-up periods for both groups were greater than 0.7.

4.1. Comparing Mean Periotest Readings (PTV) between the Nonsubmerged (NS) and the Submerged (S) Group for the Ball Attachment Group at Different Follow-Up Intervals. There was no statically significant difference between the mean 
TABLE 1: The distribution of patients throughout the follow-up intervals for all groups of patients.

\begin{tabular}{|c|c|c|c|c|c|}
\hline & \multirow{2}{*}{$\begin{array}{c}3 \text { months after } \\
\text { healing }\end{array}$} & \multicolumn{2}{|c|}{ Submerged } & \multicolumn{2}{|c|}{ Nonsubmerged } \\
\hline & & Ball group & $\begin{array}{l}\text { CM-LOC } \\
\text { group }\end{array}$ & Ball group & $\begin{array}{l}\text { CM-LOC } \\
\text { group }\end{array}$ \\
\hline Number of patients & 71 & 15 & 18 & 19 & 19 \\
\hline Number of males & 50 & 11 & 14 & 11 & 14 \\
\hline Number of females & 21 & 4 & 4 & 8 & 5 \\
\hline Mean age of males (years) & 60.4 & 61.8 & 59.3 & 59.1 & 61.7 \\
\hline Mean age of females (years) & 60.8 & 64.75 & 58.5 & 63.1 & 57.2 \\
\hline Number of patients who refused Periotest reading & & $\begin{array}{l}3 \text { patients } \\
2 \text { males } \\
1 \text { female }\end{array}$ & $\begin{array}{l}3 \text { patients } \\
\text { All males }\end{array}$ & $\begin{array}{l}4 \text { patients } \\
\text { All males }\end{array}$ & $\begin{array}{l}5 \text { patients } \\
2 \text { males } \\
3 \text { females }\end{array}$ \\
\hline Number of dropouts at 3-month follow-up & & $\begin{array}{c}1 \text { patient died } \\
\text { Male } \\
2 \text { patients }\end{array}$ & - & - & $\begin{array}{l}1 \text { patient } \\
\text { Male }\end{array}$ \\
\hline Number of dropouts at 6-month follow-up & & $\begin{array}{c}1 \text { male } \\
1 \text { female }\end{array}$ & - & - & - \\
\hline Number of dropouts at 9-month follow-up & & $\begin{array}{l}1 \text { patient died } \\
1 \text { male }\end{array}$ & - & - & $\begin{array}{l}1 \text { patient died } \\
1 \text { male }\end{array}$ \\
\hline Number of dropouts at 12 -month follow-up & & - & - & - & - \\
\hline Number of dropouts at 24-month follow-up & & - & $\begin{array}{l}2 \text { patients } \\
\text { All males }\end{array}$ & $\begin{array}{c}1 \text { patient (hospitalized) } \\
\text { Female }\end{array}$ & $\begin{array}{c}2 \text { patients } \\
\text { (hospitalized) } \\
\text { All males }\end{array}$ \\
\hline
\end{tabular}

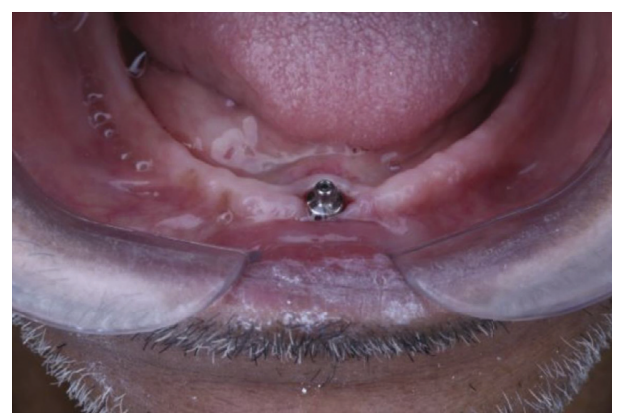

Figure 2: Ball attachment (Zimmer Company).

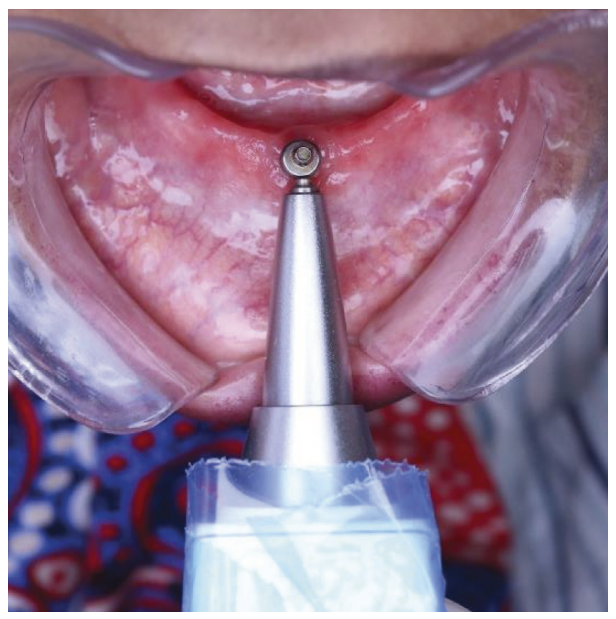

FIgURe 3: Measurement of Periotest values (PTV) of attachment using Periotest M.

PTV readings of the NS and S groups for the ball attachment throughout the 24-month follow-up. At the day of pickup, which is considered to be baseline value, the NS group has recorded higher mean PTV readings than the $S$ group $(-4.471 \pm 1.489,-4.391 \pm 1.4727(p=0.913))$ (Table 3 and Figure 5). At 3-month follow-up, the mean PTV readings for 


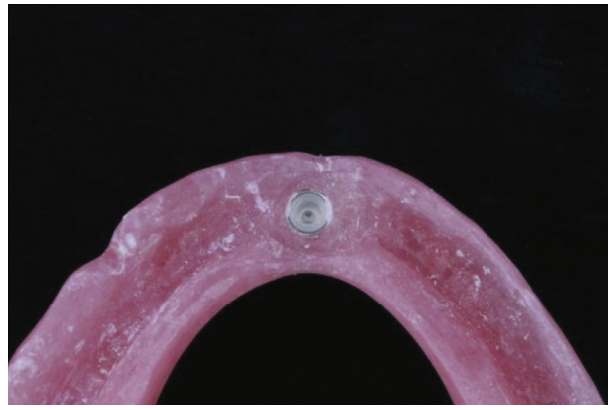

Figure 4: The nylon cap of ball attachment picked up in the fitting surface of the denture.

TABle 2: The interobserver consistency using Cronbach's alpha statistics. NS: nonsubmerged and S: submerged.

\begin{tabular}{|c|c|c|c|c|c|c|}
\hline & $\begin{array}{c}3 \text { months after } \\
\text { healing }\end{array}$ & $\begin{array}{l}\text { 3-month } \\
\text { follow-up }\end{array}$ & $\begin{array}{l}\text { 6-month } \\
\text { follow-up }\end{array}$ & $\begin{array}{l}\text { 9-month } \\
\text { follow-up }\end{array}$ & $\begin{array}{l}\text { 12-month } \\
\text { follow-up }\end{array}$ & $\begin{array}{l}\text { 24-month } \\
\text { follow-up }\end{array}$ \\
\hline Cronbach's alpha NS group & 0.965 & 0.991 & 0.995 & 0.969 & 0.975 & 0.953 \\
\hline Cronbach's alpha $\mathrm{S}$ group & 0.946 & 0.981 & 0.997 & 0.957 & 0.995 & 0.979 \\
\hline
\end{tabular}

TABLE 3: The mean $=M$ and standard deviation $=S D$ for the nonsubmerged $=$ NS and submerged $=S$ groups of patients for the ball at tachment group. $p$ value $\leq 0.05$ is considered statistically significant $\left(^{*}\right)$.

\begin{tabular}{lccccccc}
\hline & & $\begin{array}{c}\text { Baseline } \\
\text { (at the day of pickup) }\end{array}$ & $\begin{array}{c}\text { 3-month } \\
\text { follow-up }\end{array}$ & $\begin{array}{c}\text { 6-month } \\
\text { follow-up }\end{array}$ & $\begin{array}{c}\text { 9-month } \\
\text { follow-up }\end{array}$ & $\begin{array}{c}\text { 12-month } \\
\text { follow-up }\end{array}$ & $\begin{array}{c}\text { 24-month } \\
\text { follow-up }\end{array}$ \\
\hline \multirow{2}{*}{ NS } & M & -4.471 & -4.84 & -4.507 & -4.808 & -4.753 & -5.730 \\
& SD & 1.489 & 1.326 & 1.3528 & 1.7689 & 1.7082 & 1.7804 \\
\hline \multirow{2}{*}{$\mathrm{S}$} & $\mathrm{M}$ & -4.391 & -4.67 & -4.772 & -5.314 & -5.518 & -5.855 \\
& $\mathrm{SD}$ & 1.4727 & 1.194 & 1.1256 & 1.1596 & 1.2521 & 1.2581 \\
\hline \multicolumn{2}{l}{$p$ value } & & 0.913 & 0.732 & 0.801 & 0.451 & 0.246 \\
\hline
\end{tabular}

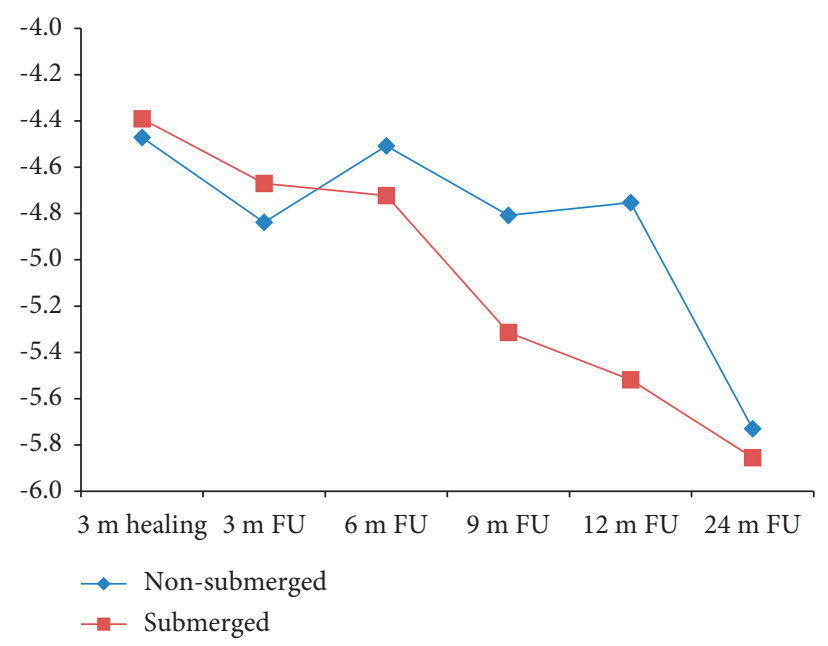

FIGURE 5: Mean PTV between NS and S in the ball attachment group.

the NS group were still higher than those for the $S$ group. Then, starting from 6-month follow-up, the mean PTV readings for the $S$ group was higher than those for the NS group throughout the 9-, 12-, and 24-month follow-up $(-5.730 \pm 1.7804,-50855 \pm 1.2581(p=0.1)$ ) (Table 3 and Figure 5).
4.2. Changes in Mean Periotest Readings (PTV) between the Nonsubmerged (NS) and the Submerged (S) Group for the Ball Attachment Group at Different Follow-Up Intervals. When having a closer look at the changes of mean PTV readings for the ball attachment in the first 6 months, 12 months, and 24 months from baseline, it is clear that 
there has been an improvement in the mean PTV readings for both the NS and S group with no statically significant differences between them. In the first 6 months from baseline, the change in mean PTV readings was slightly greater in the NS group than that in the S group, while after 12 months and 24 months, the change in PTV readings was greater in the $S$ group than that in the NS group showing the greatest improvement at 12 -month follow-up $(-0.454 \pm 1.6525,-1.775 \pm 1.6637(p=0.064))$ (Table 4 and Figure 6).

\section{Discussion}

Implant stability is one of the important parameters that would influence the successful osseointegration of dental implants. Primary implant stability is the mechanical stability, whereas secondary implant stability is the biological phenomena and is the result of osseointegration [38]. Several methods have been used to measure primary and secondary implant stability, but Resonance Frequency Analysis (RFA) using Osstell and Periotest has been the most noninvasive method commonly used to objectively monitor implant stability at different observation periods [39-41]. In the present study, the Periotest was used to monitor the changes in secondary implant stability because the Osstell would require the smart peg to be attached to the implant, and so, that would require unscrewing of the attachment each time during measurement, so that was not applicable. Zix et al. have proved that the Periotest is more user friendly and time and cost efficient because the superstructure should not be removed when performing the measurements [42]. Despite the fact that both instruments are used to evaluate stability, Meredith et al. have reported that the Periotest has low reproducibility and sensitivity [43], while on the other hand, several studies concluded that the Periotest is a reliable method to objectively determine implant stability $[15,44-52]$; furthermore, Khalaila et al. have concluded that the Periotest is a reliable tool for assessing implant stability and it would provide predictive information about marginal bone loss [53].

Interoperator and interinstrument variability have been considered to affect the Periotest scores such as the angulation and positioning of the device hand piece (horizontal distance and angle of the implant) [54]. In the following trial, the Periotest was held as a "pen grip" in the anterior area being perpendicular at the midbuccal area of the attachment as was described in the Periotest user manual by Schulte and Lukas [55] concluding that a single Periotest measurement will not allow prognosis for the stability of an implant, and so, that was the reason that 5 readings were recorded for each patient, and an average reading was then recorded in the patients file.

The bone quality and quantity are important factors that influence the primary implant stability. The more dense the bone, the better the initial stability [56]. In the present study, all implants were installed in the midline of the anterior mandible which is considered to be of dense bone as classified by Lekhom and Zarb [57], so all of the installed implants in both the submerged and nonsubmerged groups were of high initial stability with a mean PTV reading ranging from -4.4 to -5.8 ; Olive and Aparicio further confirmed that the PTV readings of dental implants lie between a narrow zone of -5 to +5 , where -5 was considered to be high stability [44]. The initial stability will consequently influence secondary implant stability [58]; that is the reason why the PTV readings recorded in both groups, the submerged and nonsubmerged groups, after 3 months of healing were of high secondary stability, as the more negative values of the Periotest indicates greater implant stability [59]. Truhlar et al. concluded that the PTV at secondstage surgery is the best estimate for the Bone-ImplantContact (BIC), as PTV determines implant stability and, more specifically, BIC which is mainly influenced by bone quality [51].

The results of the present trial are part of the randomized clinical trial that has randomized the patients at the day of pickup using sealed envelopes into two groups: ball and CM-LOC attachment. The results of the ball attachment was the scope of this clinical trial, mainly because the ball attachment has been used in several studies to retain the mandibular single implant retained overdenture and have achieved reliable outcomes $[24,31-34]$. Very few studies have addressed the changes in stability for the NS and S groups using ball attachment, so that was the reason this clinical trial was conducted to add to the outcomes of the ball attachment used in a single implant retained overdenture.

There has been an improvement in PTV readings for the NS and the $S$ group from the baseline (day of pickup) till 24month follow-up without any significant difference between the groups. The PTV readings for the NS group was initially greater PTV at baseline (day of pickup) till 3-month followup when compared to the $S$ group; then, starting from 6month follow-up till 24-month follow-up, the $S$ group has shown greater PTV when compared to NS. An explanation for this is that, during the 3-month healing period, the NS group had a healing abutment and the fitting surface of the denture was relieved by applying a soft liner to help reduce the forces falling on the installed implant for successful osseointegration. The NS group was subjected to more mechanical stimulation than the $S$ group; this mechanical stimulation may have enhanced bone formation [60-62] in the NS than the S group. Branemark et al. have reported that new bone formed under loading conditions [63] consisted mainly of mature lamellar bone which is of greater density than the new bone formed under unloaded conditions; this phenomena has been referred to "form follows function" [64], so initially, the NS group had higher PTV readings than the $S$, while for the $S$ group, the PTV readings have started to show greater scores after the pickup and loading of the attachments which have resulted in physiologic mechanical stimulation that consequently led to mature lamellar bone formation and, thus, greater bone to implant contact which consequently improved the PTV readings over 24-month follow-up. It is clear from the present study that, at 6-, 12-, and 24-month follow-up, the $\mathrm{S}$ has shown a greater improvement in the mean change in PTV readings than the NS as this would come in agreement with the work of Levy et al. 
TABLE 4: The mean $=M$ and standard deviation $=S D$ for the nonsubmerged $=\mathrm{NS}$ and submerged $=\mathrm{S}$ groups of patients for the ball at tachment group. $p$ value $\leq 0.05$ is considered statistically significant $\left(^{*}\right)$.

\begin{tabular}{llccr}
\hline & & Baseline 6-month follow-up & Baseline 12-month follow-up & Baseline to 24-month follow-up \\
\hline \multirow{2}{*}{ NS } & M & -0.346 & -0.454 & -1.412 \\
& SD & 1.1927 & 1.6525 & 1.9129 \\
\hline \multirow{2}{*}{ S } & M & -0.333 & -1.775 & -1.963 \\
& SD & 1.9947 & 1.6637 & 2.4278 \\
\hline
\end{tabular}

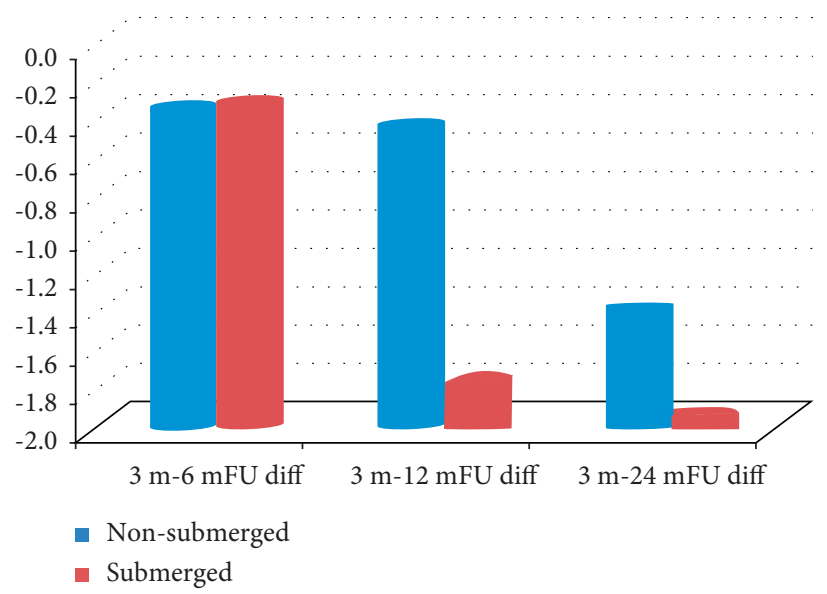

Figure 6: Mean PTV difference between NS and S in the ball attachment group.

where histomorphometric analysis revealed that bone-implant contact is greater for the submerged protocol [65].

\section{Conclusions}

Both the nonsubmerged and the submerged healing protocol have resulted in reliable Periotest readings using ball attachment for a single implant retained overdenture. The submerged group has resulted in a greater improvement change in Periotest readings after the 12- and 24-month follow-up period when compared to the nonsubmerged group although this improvement was not statistically significant.

6.1. Clinical Significance. The submerged healing protocol using ball attachment for a single implant retained mandibular overdenture would yield higher secondary stability than the nonsubmerged protocol after 24-month follow-up.

\section{Abbreviations}

PTV: $\quad$ Periotest damping effect

CM-LOC: Cendres and Metaux Locator

NS: $\quad$ Nonsubmerged

S group: Submerged.

\section{Data Availability}

A protocol for the randomized clinical study is available from the corresponding author and would be sent when required.

\section{Conflicts of Interest}

Ahmed Salah and Karim Foda, DDS, Ms, are working as lecturers in the Prosthodontic Department, Faculty of Dentistry, Cairo University. Mohamed Farouk, DDS, Ms, is an associate professor in the Prosthodontics Department, Faculty of Dentistry, Cairo University. Marwa Abdel Aal, DDS Ms, is a lecturer in the Prosthodontics Department, Faculty of Dentistry, Cairo University. Amr Ahmed Naguib, DDS, Ms, is a lecturer in the Prosthodontics Department, Faculty of Dentistry, Cairo University. Nouran A. Nabi, DDS, Ms, is an associate professor in the Prosthodontics Department, Faculty of Dentistry, Cairo University.

\section{Authors' Contributions}

Ahmed Salah and Karim Foda were responsible for recording of the Periotest values for all groups of patients at the different follow-up intervals throughout 24-month follow-up, E-mail: ahmed.sherif@dentistry.cu.edu.eg and karimfoda@hotmail.com. Mohamed Farouk was responsible for reviewing and editing of the manuscript, E-mail: mohamed.abdalla@dentistry.cu.edu.eg. Marwa Abdel Aalwas responsible for installing all of the implants, E-mail: marwa.abdelaal1@ gmail.com. Amr Ahmed Naguib was responsible for the randomization of patients using sealed envelopes, and he was responsible for preparing all of the envelopes and for arranging the appointments for the different follow-ups of all recruited patients, E-mail: amr.naguib@dentistry.cu.edu.eg. Nouran A. Nabi was responsible for monitoring all of the clinical steps and interpretation of the data. 


\section{Acknowledgments}

The authors would like to acknowledge Cendres \& Metaux Company for supplying the study with the CM-LOC attachment as a grant. This study is a part of the GESEED program, a research collaboration between the Department of Prosthodontics, Propaedeutics, and Dental Materials, Christian-Albrechts University of Kiel, Germany, and the Faculty of Dentistry, Cairo University, Egypt, funded by the German Academic Exchange Service (Deutscher Akademischer Austauschdienst, DAAD, Germany) and the Science and Technology Development Fund (STDF, Egypt), Project no. 26420. All materials used in the trials, implants, dentures, and ball attachment, were funded by the four authors: Marwa abdel Aal, Karim, Foda, Ahmed Salah, and Amr Naguib. The Science and Technology Development Fund (STDF, Egypt) (Project no. 26420) has funded the mobility of the German staff to monitor the study.

\section{References}

[1] P.-I. Brånemark, U. Breine, R. Adell, B. O. Hansson, J. Lindström, and $\AA$. Ohlsson, "Intra-osseous anchorage of dental prostheses: I. experimental studies," Scandinavian Journal of Plastic and Reconstructive Surgery, vol. 3, no. 2, pp. 81-100, 1969.

[2] P. I. Brånemark, B. O Hansson, R Adell et al., "Osseointegrated implants in the treatment of the edentulous jaw. Experience from a 10-year period," Scandinavian Journal of Plastic and Reconstructive Surgery. Supplementum, vol. 16, pp. 1-132, 1977.

[3] N. Enkling, P. Jöhren, T. Klimberg et al., "Open or submerged healing of implants with platform switching: a randomized, controlled clinical trial," Journal of Clinical Periodontology, vol. 38, no. 4, pp. 374-384, 2011.

[4] E. Mellati, S. Chen, H. Davies, W. Fitzgerald, and I. Darby, "Healing of bio-ossgrafted marginal gaps at implants placed into fresh extraction sockets of incisor teeth in dogs: a study on the effect of submerged vs. non-submerged healing," Clinical Oral Implants Research, vol. 26, no. 5, pp. 553-562, 2015.

[5] P. Åstrand, B. Engquist, B. Anzén et al., "Nonsubmerged and submerged implants in the treatment of the partially edentulous maxilla," Clinical Implant Dentistry and Related Research, vol. 4, no. 3, pp. 115-127, 2002.

[6] N. Ferrigno, M. Laureti, S. Fanali, and G. Grippaudo, "A longterm follow-up study of non-submerged ITI implants in the treatment of totally edentulous jaws," Clinical Oral Implants Research, vol. 13, no. 3, pp. 260-273, 2002.

[7] E. Romeo, D. Lops, E. Margutti, M. Ghisolfi, M. Chiapasco, and G. Vogel, "Long-term survival and success of oral implants in the treatment of full and partial arches: a 7-year prospective study with the ITI dental implant system," The International Journal of Oral \& Maxillofacial Implants, vol. 19, pp. 247-259, 2004.

[8] D. Buser, R. Mericske-Stern, J. P. Bernard et al., "Long-term evaluation of non-submerged ITI implants. Part 1: 8-year life table analysis of a prospective multi-center study with 2359 implants," Clinical Oral Implants Research, vol. 8, no. 3, pp. 161-172, 1997.

[9] D. Buser, R. Mericske-Stern, K. Dula, and N. P. Lang, "Clinical experience with one-stage, non-submerged dental implants," Advances in Dental Research, vol. 13, no. 1, pp. 153-161, 1999.
[10] J. P. Becktor, S. Isaksson, and C. Billström, “A prospective multicenter study using two different surgical approaches in the mandible with turned brånemark implants: conventional loading using fixed prostheses," Clinical Implant Dentistry and Related Research, vol. 9, no. 4, pp. 179-185, 2007.

[11] M. Al-sabbagh, W. Eldomiaty, and Y. Khabbaz, "Can osseointegration be achieved without primary stability?" Dental Clinics of North America, vol. 63, no. 3, pp. 461-473, 2019.

[12] A. N. Natali, E. L. Carniel, and P. G. Pavan, "Investigation of viscoelastoplastic response of bone tissue in oral implants press fit process," Journal of Biomedical Materials Research Part B: Applied Biomaterials, vol. 91B, no. 2, pp. 868-875, 2009.

[13] G. Greenstein, J. Cavallaro, G. Romanos, and D. Tarnow, "Clinical recommendations for avoiding and managing surgical complications associated with implant dentistry: a review," Journal of Periodontology, vol. 79, no. 8, pp. 1317-1329, 2008.

[14] A. Monje, A. Ravidà, H.-L. Wang, J. Helms, and J. Brunski, "Relationship between primary/mechanical and secondary/ biological implant stability," The International Journal of Oral \& Maxillofacial Implants, vol. 34, pp. s7-s23, 2019.

[15] N. Meredith, "Assessment of implant stability as a prognostic determinant," The International Journal of Prosthodontics, vol. 11, pp. 491-501, 1998.

[16] J.-h. Oh and M. Chang, "Comparison of initial implant stability measured by resonance frequency analysis between different implant systems," The Journal of the Korean Academy of Periodontology, vol. 38, no. 3, pp. 529-534, 2008.

[17] W. Schulte, B. d'Hoedt, D. Lukas et al., "Periotest-a new measurement process for periodontal function," Zahnärztliche Mitteilungen, vol. 73, pp. 1229-1230, 1983.

[18] W. Schulte and D. Lukas, "Periotest to monitor osseointegration and to check the occlusion in oral implantology," Journal of Oral Implantology, vol. 19, pp. 23-32, 1993.

[19] J. M. Thomason, S. A. M. Kelly, A. Bendkowski, and J. S. Ellis, "Two implant retained overdentures-a review of the literature supporting the McGill and York consensus statements," Journal of Dentistry, vol. 40, no. 1, pp. 22-34, 2012.

[20] J. M. Thomason, "The McGill consensus statement on overdentures. Mandibular 2-implant overdentures as first choice standard of care for edentulous patients," The European Journal of Prosthodontics and Restorative Dentistry, vol. 10, no. 3, pp. 95-96, 2002.

[21] J. S. Feine, G. E. Carlsson, M. A. Awad, A. Chehade, W. J. Duncan, and S. Gizani, "The McGill consensus statement on overdentures," Quintessence International, vol. 34, pp. 78-79, 2003.

[22] S. Harder, S. Wolfart, C. Egert, and M. Kern, "Three-year clinical outcome of single implant-retained mandibular overdentures-Results of preliminary prospective study," Journal of Dentistry, vol. 39, no. 10, pp. 656-661, 2011.

[23] T. Cheng, G. Sun, J. Huo, X. He, Y. Wang, and Y.-F. Ren, "Patient satisfaction and masticatory efficiency of single implant-retained mandibular overdentures using the stud and magnetic attachments," Journal of Dentistry, vol. 40, no. 11, pp. 1018-1023, 2012.

[24] G. Cordioli, Z. Majzoub, and S. Castagna, "Mandibular overdentures anchored to single implants: a five-year prospective study," The Journal of Prosthetic Dentistry, vol. 78, no. 2, pp. 159-165, 1997.

[25] S. R. Bryant, J. N. Walton, and M. I. MacEntee, "A 5-year randomized trial to compare 1 or 2 implants for implant 
overdentures," Journal of Dental Research, vol. 94, no. 1, pp. 36-43, 2015.

[26] M. Kern, C. Behrendt, E. Fritzer et al., "5-year randomized multicenter clinical trial on single dental implants placed in the midline of the edentulous mandible," Clinical Oral Implants Research, vol. 32, no. 2, pp. 212-221, 2021.

[27] Y. Maeda, M. Horisaka, and K. Yagi, "Biomechanical rationale for a single implant-retained mandibular overdenture: an in vitro study," Clinical Oral Implants Research, vol. 19, pp. 271-275, 2008.

[28] J. N. Walton, N. Glick, and M. I. Macentee, "A randomized clinical trial comparing patient satisfaction and prosthetic outcomes with mandibular overdentures retained by one or two implants," The International Journal of Prosthodontics, vol. 22, pp. 331-339, 2009.

[29] M. Cune, F. van Kampen, A. van der Bilt, and F. Bosman, "Patient satisfaction and preference with magnet, bar-clip, and ball-socket retained mandibular implant overdentures: a cross-over clinical trial," The International Journal of Prosthodontics, vol. 18, pp. 99-105, 2005.

[30] M. R. Fenlon, R. M. Palmer, P. Palmer, J. T. Newton, and M. Sherriff, "A prospective study of single stage surgery for implant supported overdentures," Clinical Oral Implants Research, vol. 13, pp. 365-370, 2002.

[31] G. J. Liddelow and P. J. Henry, "A prospective study of immediately loaded single implant-retained mandibular overdentures: preliminary one year results," The Journal of Prosthetic Dentistry, vol. 97, pp. 126-137, 2007.

[32] G. B. Schneider and W. J. Synan, "Use of a single implant to retain a mandibular complete overdenture on the compromised atrophic alveolar ridge: a case report," Special Care in Dentistry, vol. 31, pp. 138-143, 2011.

[33] N. H. Alsabeeha, A. G. Payne, R. K. De Silva, and W. M. Thomson, "Mandibular single-implant overdentures: preliminary results of a randomised-control trial on early loading with different implant diameters and attachment systems," Clinical Oral Implants Research, vol. 22, pp. 330337, 2011.

[34] N. Alsabeeha, A. G. Payne, R. K. De Silva, and M. V. Swain, "Mandibular single-implant overdentures: a review with surgical and prosthodontic perspectives of a novel approach," Clinical Oral Implants Research, vol. 20, pp. 356-365, 2009.

[35] M. Aal, M. El Far, N. M. Sheta, A. Fayyad, E. El Desouky, and N. Abdel Nabi, "Correlation of implant stability between two non-invasive methods using submerged and non submerged healing protocols; a randomized clinical trial," Journal of Oral Implantology, vol. 46, pp. 571-579, 2020.

[36] J. L. Calvo-Guirado, M. Satorres-Nieto, A. Aguilar-Salvatierra et al., "Influence of surface treatment on osseointegration of dental implants: histological, histomorphometric and radiological analysis in vivo," Clinical Oral Investigations, vol. 19, pp. 509-517, 2015.

[37] N. Wei, S. Bin, Z. Jing, S. Wei, and Z. Yingqiong, "Influence of implant surface topography on bone-regenerative potential and mechanical retention in the human maxilla and mandible," American Journal of Dentistry, vol. 27, pp. 171-176, 2014.

[38] M. Atsumi, S. H. Park, and H. L. Wang, "Methods used to assess implant stability: current status," The International Journal of Oral \& Maxillofacial Implants, vol. 22, pp. 743-754, 2007.

[39] L. Sennerby and N. Meredith, "Implant stability measurements using resonance frequency analysis: biological and biomechanical aspects and clinical implications," Periodontology, vol. 47, pp. 51-66, 20002008.

[40] P. O. Ostman, M. Hellman, I. Wendelhag, and L. Sennerby, "Resonance frequency analysis measurements of implants at placement surgery," The International Journal of Prosthodontics, vol. 19, pp. 77-83, 2006.

[41] M. Hayashi, C. Kobayashi, H. Ogata, M. Yamaoka, and B. Ogiso, "A no-contact vibration device for measuring implant stability," Clinical Oral Implants Research, vol. 21, pp. 931-936, 2010.

[42] J. Zix, S. Hug, G. Kessler-Liechti, and R. Mericske-Stern, "Measurement of dental implant stability by resonance frequency analysis and damping capacity assessment: comparison of both techniques in a clinical trial," The International Journal of Oral \& Maxillofacial Implants, vol. 23, pp. 525-530, 2008.

[43] N. Meredith, K. Book, B. Friberg, T. Jemt, and L. Sennerby, "Resonance frequency measurements of implant stability in vivo. A cross-sectional and longitudinal study of resonance frequency measurements on implants in the edentulous and partially dentate maxilla," Clinical Oral Implants Research, vol. 8, pp. 226-233, 1997.

[44] J. Olive and C. Aparicio, "Periotest method as a measure of osseointegrated oral implant stability," The International Journal of Oral \& Maxillofacial Implants, vol. 5, pp. 390-400, 1996.

[45] I. E. Naert, D. Rosenberg, D. Van Steenberghe, J. A. Tricio, and M. Nys, "The influence of splinting procedures on the periodontal and peri-implant tissue damping characteristics. A longitudinal study with the periotest device," Journal of Clinical Periodontology, vol. 22, pp. 703-708, 1995.

[46] J. Tricio, P. Laohapand, D. Van Steenberghe, M. Quirynen, and I. Naert, "Mechanical state assessment of the implantbone continuum: a better understanding of the periotest method," The International Journal of Oral \& Maxillofacial Implants, vol. 10, pp. 43-49, 1995.

[47] J. Tricio, D. Van Steenberghe, D. Rosenberg, and L. Duchateau, "Implant stability related to insertion torque force and bone density: an invitro study," The Journal of Prosthetic Dentistry, vol. 74, pp. 608-612, 1995.

[48] D. Van Steenberghe, J. Tricio, I. Naret, and M. Nys, "Damping characterstics of bone-to-implant interface. A clinical study with periotest device," Clinical Oral Implants Research, vol. 6, pp. 31-39, 1995.

[49] C. Aparicio, "The use of the periotest value as the initial success criteria of an implant: 8-year report," The International Journal of Periodontics and Restorative Dentistry, vol. 17, pp. 150-161, 1997.

[50] L. Walker, H. F. Morris, and S. Ochi, "Periotest values of dental implants in the first 2 years after second-stage surgery: DICRG interim report no.8 dental Implant clinical research group," Implant Dentistry, vol. 6, pp. 207-212, 1997.

[51] R. S. Truhlar, H. F. Morris, and S. Ochi, "Stability of the boneimplant complex. Results of longitudinal testing to 60 months with the periotest devices on endosseous dental implants," Annals of Periodontology, vol. 5, pp. 42-55, 2000.

[52] P. A. Schnitman and J. W. Hwang, "To immediately load, expose, or submerge in partial edentulism: a study of primary stability and treatment outcome," The International Journal of Oral \& Maxillofacial Implants, vol. 26, pp. 850-859, 2011.

[53] W. Khalaila, M. Nasser, and Z. Ormianer, "Evaluation of the relationship between periotest values, marginal bone loss, and stability of single dental implants: a 3 year-prospective study," The Journal of Prosthetic Dentistry, vol. 124, pp. 183-188, 2019. 
[54] N. Meredith, B. Friberg, L. Sennerby, and C. Aparicio, "Relationship between contact time measurements and PTV values when using the periotest to measure implant stability," The International Journal of Prosthodontics, vol. 11, pp. 269275, 1998.

[55] W. Schulte and D. Lukas, "The periotest method," International Dental Journal, vol. 42, pp. 433-440, 1992.

[56] T. Jemt, U. Lekholm, and R. Adell, "Osseointegrated implants in the treatment of partially edentulous patients: a preliminary study on 876 consecutively placed fixtures," The International Journal of Oral \& Maxillofacial Implants, vol. 4, pp. 211-217, 1989.

[57] U. Lekholm and G. A. Zarb, "Patient selection and preparation," in Tissue Integrated Prostheses: Osseointegration in Clinical Dentistry, P. I. Branemark, G. A. Zarb, and T. Albrektsson, Eds., pp. 199-209, Quintessence Publishing Company, Chicago, IL, USA, 1985.

[58] L. Sennerby and J. Roos, "Surgical determinants of clinical success of osseointegrated oral implants: a review of the literature," The International Journal of Prosthodontics, vol. 11, pp. 408-420, 1998.

[59] S. Soicu, D. Bratu, and I. Borsanu, "Damping capacity assessment versus resonance frequency analysis in the determination of dental implant stability," Timişoara Medical Journal, vol. 60, pp. 109-115, 2010.

[60] G. E. Romanos, C. G. Toh, C. H. Siar, and D. Swaminathan, "Histologic and histomorphometric evaluation of peri-implant bone subjected to immediate loading: an experimental study with Macaca fascicularis," The International Journal of Oral \& Maxillofacial Implants, vol. 17, pp. 44-51, 2002.

[61] G. E. Romanos, C. G. Toh, C. H. Siar, H. Wicht, H. Yacoob, and G. H. Nentwig, "Bone-implant interface around titanium implants under different loading conditions: a histomorphometrical analysis in the Macaca fascicularis monkey," Journal of Periodontology, vol. 74, pp. 1483-1490, 2003.

[62] L. Zhao, Z. Wu, and Y. Zhang, "Low-magnitude mechanical vibration may be applied clinically to promote dental implant osseointegration," Medical Hypotheses, vol. 72, pp. 451-452, 2009.

[63] P.-I. Branemark, K. Grondahl, and B. Branemark, "Why osseointegration works and how it did in the first patients treated. Basic facts and philosophical thoughts," in The Osseointegration Book 2005. From Calvarium to Calcaneus, P.-I. Branemark, Ed., p. 38, Quintessence, Berlin, Germany, 2005.

[64] W. E. Roberts, F. R. Helm, K. J. Marshall, and R. K. Gongloff, "Rigid endosseous implants for orthodontic and orthopedic anchorage," The Angle Orthodontist, vol. 59, pp. 247-256, 1989.

[65] D. Levy, D. A. Deporter, R. M. Piliar, P. A. Watson, and N. Valiquette, "Initial healing in the dog of submerged versus non-submerged porous-coated endosseous dental implants," Clinical Oral Implants Research, vol. 7, pp. 101-110, 1996. 